JURNAL SONDIR

p-ISSN 1979-2832

e-ISSN 2746-8275

https://ejournal.itn.ac.id/index.php/sondir

vol.5 No.2 Tahun 2021, pp. 1-9

\title{
PERENCANAAN BOEZEM DAN POMPA DALAM PENANGAN BANJIR DI KABUPATEN PASURUAN JAWA TIMUR
}

\author{
Naufal Hisyam Erwanto', Erni Yulianti², dan Sriliani Surbakti ${ }^{3}$ \\ ${ }^{1}$ Jurusan Teknik Sipil, ITN Malang, Jalan Bendungan Sigura-gura no 02 Malang \\ Email: naufalhisyam@gmail.com \\ ${ }^{2}$ Jurusan Teknik Sipil, ITN Malang, Jalan Bendungan Sigura-gura no 02 Malang \\ Email:abdulgani@yahoo.co.id \\ ${ }^{3}$ Jurusan Teknik Sipil, ITN Malang, Jalan Bendungan Sigura-gura no 02 Malang
}

\begin{abstract}
Flood is a water issues that effect to material and non material lost. While there are no correct solution, it will be made greater damage on next day. From many act on infrasucture sides like river normalisation, drainage system, and reservoir construction these called boezem. Boezem planning as an alternative flood disaster in Pasuruan District East Java province will accommodate water caused high rainfall on 50 years period $235,8669 \mathrm{~m}^{3} / \mathrm{second}$. Planning of boezem calculated with high rainfall prediction on 50 years, and with discharge prediction on 50 years by rational method $235,8669 \mathrm{~m}^{3} / \mathrm{second}$. And continued with flood routing calculation by HSS. Nakayasu on 50 years period. Based on calculation storage that can accommodate the water is $47973,89 \mathrm{~m}^{3}$. As complement facilities to supporting dewatering boezem pumping station and sluice gates result of boezem storage will be plan $48.000 \mathrm{~m}^{3}$. For dewatering purpose, boezem need submersible pump with maximum capacity around $6600 \mathrm{~m}^{3}$ /hour as much 2 units, and 2 units too for sluice gates. Sluice gates and pumps will operated based on water level of boezem.
\end{abstract}

Keyword: Flood, discharge, boezem

\begin{abstract}
ABSTRAK
Banjir merupakan suatu permasalahan air yang dapat berakibat pada kerusakan materil dan non materil. Apabila tidak di lakukan langkah pencegahan yang tepat, maka akan terjadi kerusakan yang lebih besar dikemudian hari. Dari berbagai tindak pencegahan di bidang infrastruktur seperti normalisasi sungai, pembuatan saluran drainase, terdapat pula pembuatan danau/waduk buatan yang disebut boezem. Perencanaan boezem sebagai alternatif penanganan banjir di Kabupaten Pasuruan Provinsi Jawa Timur akan menampung air akibat limpasan air hujan pada periode rancangan 50 tahun sebesar $235,8669 \mathrm{~m}^{3} /$ detik. Perencanaan boezem di dapat dari perhitungan curah hujan rancangan periode 50 tahun sebesar $221,833 \mathrm{~mm}$, dan dengan debit banjir rancangan metode rasional periode 50 tahun $235,8669 \mathrm{~m}^{3} / \mathrm{detik}$. Kemudian dilakukan penelusuran banjir dengan inflow pada perhitungan HSS. Nakayasu kala ulang 50 tahun. Dan didapat kan nilai tampungan sebesar 47973,89 m3. Hasil dari perhitungan penelusuran banjir terhadap pompa dan pintu air didapatkan volume tampungan rencana sebesar $48.000 \mathrm{~m}^{3}$. Sebagai pelengkap untuk mendukung proses pengeringan boezem maka diperlukan pompa air dengan kapasitas maksimum $6600 \mathrm{~m}^{3} / \mathrm{jam}$ sebanyak 2 unit, dan 2 unit pintu air. Dan didapatkan pola pengoperasian pompa dan pintu air berdasarkan ketinggian air pada boezem.
\end{abstract}

Kata kunci: Banjir, debit banjir rancangan, boezem

\section{PENDAHULUAN}

Kabupaten Pasuruan terbagi atas 5 (lima) daerah aliran sungai (DAS) yakni DAS Laweyan, DAS Rejoso, DAS Welang, DAS Petung, DAS Kedunglarangan. Dari peta daerah aliran dan data karkteristik serta debit sungai utama, dapat dilihat bahwa yang menjadi sungai utama adalah Sungai Welang. Sungai Welang memiliki catchment area terbesar yaitu $518 \mathrm{~km}^{2}$, juga memiliki panjang sungai $36 \mathrm{~km}$ dan lebar $35 \mathrm{~m}$.
Kabupaten Pasuruan adalah salah satu kabupaten di Jawa Timur yang terdampak oleh bencana banjir. Dengan total penduduk 1.627.400 jiwa, 6.379 kepala keluarga (BPS Kabupaten Pasuruan, 2020) diantaranya terdampak banjir yang diakibatkan luapan Sungai Welang, dengan tinggi muka air $10-120 \mathrm{~cm}$, dan area daerah yang terendam banjir seluas $20,96 \mathrm{~km}^{2}$ (BPS Kabupaten Pasuruan, 2020). Banjir yang terjadi disebabkan curah hujan yang meningkat, serta adanya rob yang datang bersamaan. 


\section{JURNAL SONDIR}

p-ISSN 1979-2832

e-ISSN 2746-8275

https://ejournal.itn.ac.id/index.php/sondir

vol. 5 No. 2 Tahun 2021, pp.1-9

Oleh karena itu, perlu untuk diadakan pembangunan infrastruktur berupa boezem dikawasan hilir Sungai Welang beserta dengan pompanya. Karena boezem merupakan bangunan air yang menyerupai danau/waduk buatan yang dapat menampung air dengan volume besar, dilengkapi dengan bangunan pengatur debit, seperti pompa dan pintu air.

\section{LANDASAN TEORI}

\section{Boezem, pompa dan pintu air}

Boezem sendiri memiliki pengertian kolam yang bertujuan untuk menampung sementar limpasan air hujan atau air sungai ke dalam suatu kawasan. Pompa yang mana berfungsi sebagai alat pengeringan boezem yang difungsikan secara hidrolis yang mana memiliki fungsi lain yang sama dengan pintu air, yakni pengatur elevasi boezem dan pembuangan.

\section{Hidrologi}

\section{Analisa curah hujan rata-rata}

Rumus perhitungan yang digunakan adalah metode aritmatik dengan menggunakan data curah hujan harian maksimum. Dengan memperhatikan wilayah studi terdekat, maka diambil stasiun hujan Lawang, stasiun hujan Tutur, dan stasiun hujan Wonorejo.

$\overline{\mathrm{R}}=\frac{R_{1}+R_{2}+\cdots+R_{n}}{N}=\frac{1}{N} \sum R t$

Dimana :

$\mathrm{R} \quad=$ Tinggi Hujan rata-rata $\quad(\mathrm{mm})$

$\mathrm{R}_{\mathrm{t}} \quad=$ Tinggi Hujan Harian maksimum $(\mathrm{mm})$

$\mathrm{N}=$ Jumlah data

\section{Analisa frekuensi}

Analisa frekuensi adalah analisa mengenai pengulangan suatu kejadian untuk memperkiakan atau memilih distribusi probabilitas yang akan dipakai, Parameter statistik yang dipakai adalah:

- Nilai Rata-Rata

$$
\bar{R}=\frac{\sum X}{n}
$$

- Standar Deviasi

$s=\sqrt{\frac{\sum(X-\bar{X})}{n-1}}$

- Coefficient of Variation (Koefisien variasi)

$$
C v=\frac{s}{\bar{X}}
$$

- Coefficient of skewness (koefisien kemencengan)

$C S=\frac{n \cdot \sum(X-\bar{X})^{3}}{(n-1)(n-2) S^{3}}$
- Coefficient of kurtois (Koefisien ketajaman)

$C k=\frac{n^{2} \cdot \Sigma(X-\bar{X})^{4}}{(n-1)(n-2)(n-3) S^{4}}$

Dimana:

$$
\begin{array}{ll}
\mathrm{S} & \quad=\text { Standar Deviasi } \\
\mathrm{X} & =\text { Data dalam sampel } \\
\bar{X} & =\text { Nilai rata-rata hitung } \\
\mathrm{N} & =\text { Jumlah data } \\
\mathrm{C}_{\mathrm{v}} & =\text { Koefisien variasi } \\
\mathrm{C}_{\mathrm{S}} & =\text { Koefisien Kemencengan } \\
\mathrm{C}_{\mathrm{k}} & =\text { Koefisien ketajaman }
\end{array}
$$

\section{Uji distribusi}

\section{- Uji Chi-Square}

Ujiyang dimaksudkan untuk menentukan apakah persamaan distribusi yang telah dipilih dapat mewakili analisa distibusi sampel yang dianalisa.

$X_{h}{ }^{2}=\frac{(O f-E f)^{2}}{E i}$

Keterangan:

$\mathrm{X}_{\mathrm{h}}{ }^{2}=$ Parameter Chi-Square terhitung

$\mathrm{G} \quad=$ Jumlah sub kelompok

$\mathrm{O}_{\mathrm{i}} \quad=$ Jumlah nilai pengamatan pada sub

kelopok ke i

Ei = Jumlah nilai teoritis pada sub kelompok ke i

- Uji Smirnov-Kolmogorov

Uji kecocokan Smirnov-Kolmogorov pada dasarnya sering juga disebut uji kecocokan nonparametric, karena pengujiannya tidak menggunakan distribusi tertentu.

Prosedurnya adalah sebagai berikut:

a. Urutan data (dari besar ke kecil) atau sebaliknya dan tentukan besarnya peluang dari masing masing data tersebut.

b. Tentukan nilai masing - masing peluang teoritis dari hasil penggambaran data (persamaan distribusi)

c. Dari data nilai peluang tersebut, tentukan selisih terbesar antara peluang pengamatan atau peluang teoritis.

a. Berdasarkan table 2.2 (Smirnov Kolmogorov) tentukan harga Do.

Tabel 1. Nilai Uji Kritis untuk Smirnov-Kolmogorof

\begin{tabular}{|l|l|l|l|l|}
\hline \multirow{2}{*}{$\mathrm{N}$} & \multicolumn{4}{|l|}{$\alpha$} \\
\cline { 2 - 5 } & 0.2 & 0.1 & 0.05 & 0.01 \\
\hline 5 & 0.45 & 0.51 & 0.56 & 0.67 \\
\hline 10 & 0.32 & 0.37 & 0.41 & 0.49 \\
\hline 15 & 0.27 & 0.3 & 0.34 & 0.4 \\
\hline 20 & 0.23 & 0.26 & 0.29 & 0.36 \\
\hline 25 & 0.21 & 0.24 & 0.27 & 0.32 \\
\hline
\end{tabular}




\section{JURNAL SONDIR}

p-ISSN 1979-2832

e-ISSN 2746-8275

https://ejournal.itn.ac.id/index.php/sondir vol. 5 No. 2 Tahun 2021, pp.1-9

\begin{tabular}{|l|l|l|l|l|}
\hline 30 & 0.19 & 0.22 & 0.24 & 0.29 \\
\hline 35 & 0.18 & 0.2 & 0.23 & 0.27 \\
\hline 40 & 0.17 & 0.19 & 0.21 & 0.25 \\
\hline 45 & 0.16 & 0.18 & 0.2 & 0.24 \\
\hline 50 & 0.15 & 0.17 & 0.19 & 0.23 \\
\hline $\mathrm{N}>5$ & $1.07 / \mathrm{N}$ & $1.22 / \mathrm{N}$ & $1.36 / \mathrm{N}$ & $1.63 / \mathrm{N}$ \\
0 & 0.5 & 0.5 & 0.5 & 0.5 \\
\hline
\end{tabular}

Sumber: (Soemarto, 1987)

Tabel 2. Wilayah Luas dibawah Kurva Normal

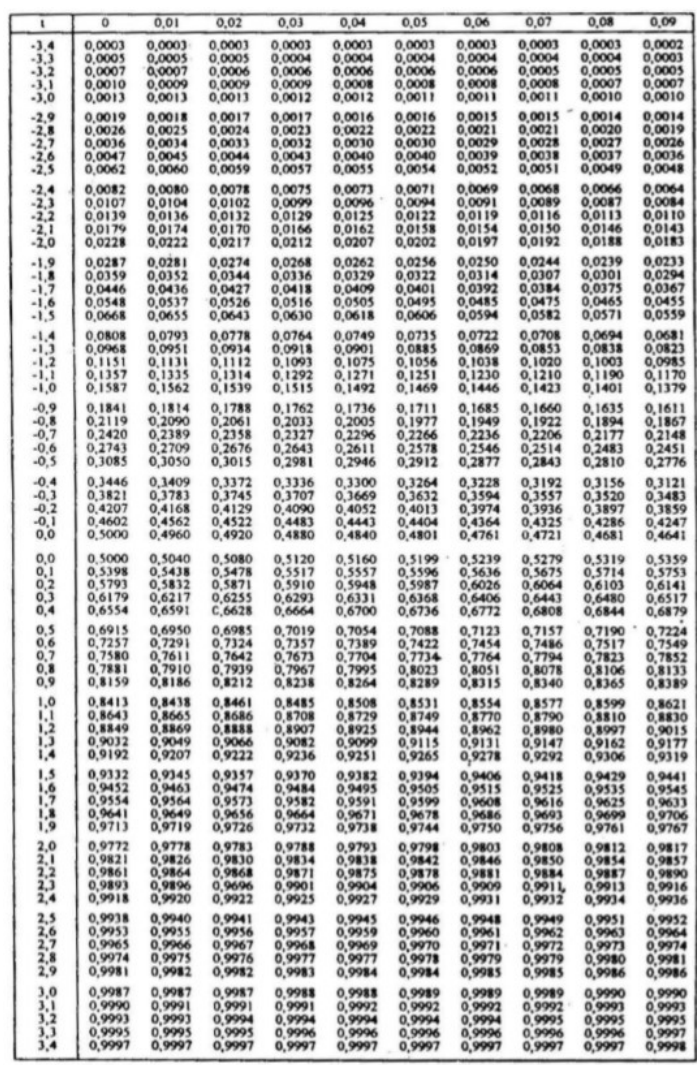

Sumber: (Soemarto, 1987)

\section{Intensitas hujan}

Analisa ini merupakan variabel kontinyu yang digambarkan dalam suatu analisa dengan persamaan distribusi peluang.

- Metode E.J Gumbel

Hujan rencana dengan periode tertentu ditentukan dengan metode Gumbel. Dengan rumus sebagai berikut:

$$
\begin{aligned}
& R_{t}=R r+K \cdot S_{S} \\
& K=\frac{Y t-Y n}{S n} \\
& Y_{T}=-\ln \left[\ln \left\{\frac{T r}{T r-1}\right\}\right]
\end{aligned}
$$

$S x=\sqrt{\frac{\sum\left(R_{i}-R_{r}\right)^{2}}{n-1}}$

Dimana:

$\mathrm{R}_{\mathrm{T}} \quad=$ Curah hujan rencana dengan periode ulang $\mathrm{T}(\mathrm{mm})$

$\mathrm{R}_{\mathrm{r}}=$ Curah hujan rata-rata hasil pengamatan $\mathrm{n}$ tahun di lapangan ( $\mathrm{mm}$ )

$\mathrm{K}=$ Frekuensi faktor

$\mathrm{S}_{\mathrm{x}}=$ Standar deviasi dari hasil pengamatan selama $\mathrm{n}$ tahun

$\mathrm{Y}_{\mathrm{T}} \quad=$ Reduced variate

$\mathrm{Y}_{\mathrm{N}} \quad=$ Reduced mean

$\mathrm{S}_{\mathrm{n}} \quad=$ Reduce standar deviasi

$\mathrm{R}_{\mathrm{i}} \quad=$ Besarnya curah hujan pada pengamatan ke

$\mathrm{N} \quad=$ jumlah pengamatan

- Metode Log Pearson Type III

Metode ini mengubah data tersebut ke dalam logaritmanya yang mana dihitung parameter statistiknya.

Langkah-langkah perhitungannya sebagai berikut:

a. Menyusun data curah hujan (R) mulai dari harga terbesar hingga terkecil

b. Mengubah sejumlah $\mathrm{N}$ data curah hujan ke dalam bentuk Logaritma, sehingga menjadi log R1, log R2, ..., $\log \mathrm{Rn}$. Selanjutnya dinyatakan $\mathrm{Xi}=\log \mathrm{Ri}$

c. Menghitung besarnya harga ratarata besaran logaritma tersebut menurut persamaan:

$$
\bar{X}=\frac{\sum x i}{n}
$$

d. Menghitung besarnya harga Cs dari besaran logaritma diatas, menurut persamaan L

e. Menghitung harga Cs dari besaran logaritma diatas, menurut persamaan:

$S d=\sqrt{\frac{\sum(x i-\bar{X})^{2}}{n-1}}$

f. Berdasarkan harga Cs dari besaran logaritma diatas, menurut persamaan:

$C s=\frac{\frac{n}{(n-1)(n-2)} \sum(x i-\bar{X})^{3}}{s d^{3}}$

g. Menghitung besarnya harga logarima dai masing-masing data curah hujan untuk suatu periode ulang tertentu dengan menggunakan persamaan:

$X_{t}=\bar{X}+K_{X} \cdot S d$ 


\section{JURNAL SONDIR}

p-ISSN 1979-2832

e-ISSN 2746-8275

https://ejournal.itn.ac.id/index.php/sondir

vol. 5 No. 2 Tahun 2021, pp.1-9

h. Jadi, perkiraan harga hujan harian maksimum untuk periode ulang $\mathrm{T}$ adalah $\mathrm{Rt}=\operatorname{antilog} \mathrm{Xt}$ atau $\mathrm{Rt}=10^{\mathrm{x}} \mathrm{T}$

\section{Debit banjir rancangan}

Metode rasional dibuat dengan mempertimbangkan bahwa banjir berasal dari hujan yang mempunyai intensitas curah hujan seragam dan merata diseluruh DAS. Metode rasional ini pada umumnya banyak digunakan untuk menghitung debit banjir pada daerah aliran sungai yang tidak terlalu luas dengan batasan hingga luas kurang dari 300 ha (Suripin, 2004). Persamaan matematik metode rasional dapat dinyatakan dalam bentuk:

$\mathrm{Q}=0,278$. C . I . A

Dimana:

$\mathrm{Q}=$ debit banjir rencana $\left(\mathrm{m}^{3} / \mathrm{dt}\right)$

$\mathrm{C}=$ koefisien pengaliran

I = intensitas hujan ( $\mathrm{mm} / \mathrm{jam})$

$\mathrm{A}=$ Catchment area $\left(\mathrm{km}^{2}\right)$

\section{Penelusuran banjir (flood routing)}

Penelusuran banjir adalah metode pendekatan untuk menentukan variasi debit terhadap waktu pada suatu titik pengamatan (Thioritz, 2009). Metode tersebut merupakan prakiraan hidrograf disuatu titik pada suatu aliran atau bagian sungai yang didasarkan atas pengamatan hidrograf di titik lain. Persamaan kontinuitas yang umum dipakai dalam penelusuran banjir adalah sebagai berikut:

$\mathrm{I}-\mathrm{Q}=\frac{d s}{d t}$

Dimana:

$\mathrm{I}=$ debit yang masuk ke dalam permulaan bagian memanjang palung sungai yang ditinjau $\left(\mathrm{m}^{3} / \mathrm{dt}\right)$

$\mathrm{Q}=$ debit yang keluar dari akhir bagian memanjang palung sungai yang ditinjau $\left(\mathrm{m}^{3} / \mathrm{dt}\right)$

$\mathrm{dS}=$ besarnya tampungan dalam bagian memanjnag palung sungai yang ditinjau

$\mathrm{dt}=$ periode penelusuran (detik, jam, atau hari)

Dengan indeks 1 merupakan keadaan mula periode penelusuran, dan indeks 2 merupakan keadaan akhir periode penelusuran, persamaan diatas dapat ditulis sedemikian rupa sehingga faktor-faktor yang diketahui ditempatkan diruas kiri (Thioritz, 2009) seperti berikut :

$$
\frac{I 1+I 2}{2} \Delta t+\left(S 1-\frac{Q 1}{2} \Delta t\right)=\left(S 2-\frac{Q 2}{2} \Delta t\right)
$$

Jika:

$\frac{S 1}{\Delta t}-\frac{Q 1}{2}=\psi 1$

$\frac{S 2}{\Delta t}+\frac{Q 2}{2}=\varphi 2$

Maka ketiga persamaan diatas menjadi:

$\frac{I 1+I 2}{2}+\psi 1=\varphi 2$

\section{METODE PENELITTIAN}

\section{Survey pendahuluan dan studi literatur}

Kabupaten Pasuruan merupakan salah satu kabupaten di Provinsi Jawa Timur yang secara geografis terletak diantara $112^{\circ} 33^{\prime} 55^{\prime \prime}$ hingga $113^{\circ} 5^{\prime} 37^{\prime \prime}$ bujur timur, $7^{\circ} 32 ’ 34^{\prime \prime}$ hingga $7^{\circ} 57^{\prime} 20^{\prime \prime}$ lintang selatan.

Dalam penelitian kali ini akan dipilih lokasi studi perencanaan yakni terbagi di Desa Semare dan Pulokerto yang mana menjadi wilayah hilir dari DAS Welang. Mengenai penempatan boezem, pompa air, dan pintu air yang akan direncanakan, akan mengacu pada tata guna lahan (land use) yang telah ada. Studi literatur meliputi kegiatan memahami teori-teori (hidrologi dan hidrolika) yang berkaitan dengan dasar yang akan digunakan dalam perencanaan.

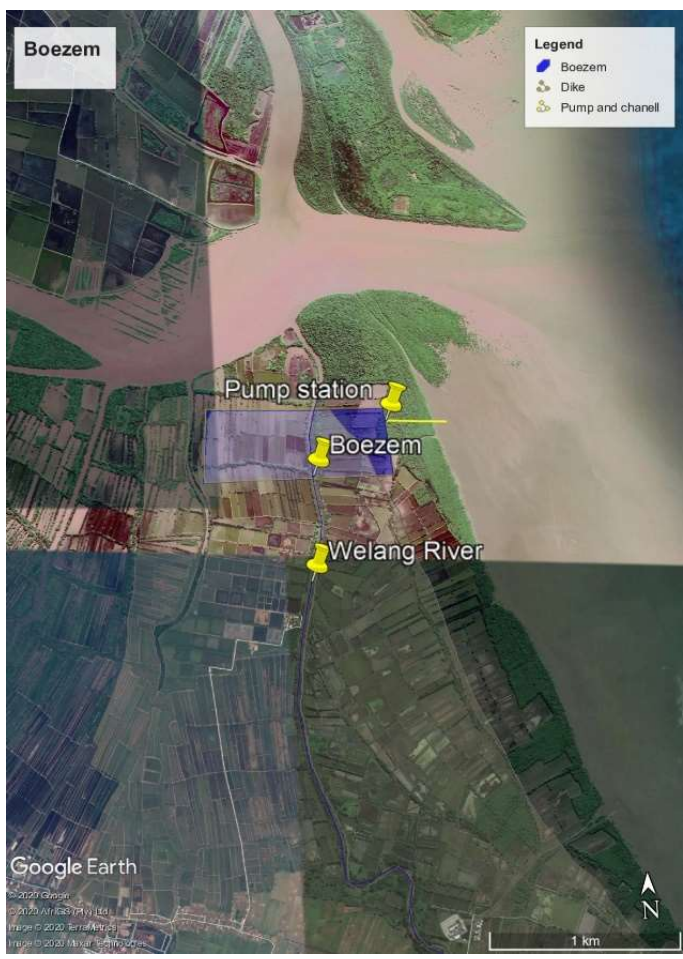

Gambar 1. Citra sateltit lokasi studi

Sumber: Google Earth 


\section{JURNAL SONDIR}

p-ISSN 1979-2832

e-ISSN 2746-8275

https://ejournal.itn.ac.id/index.php/sondir vol. 5 No. 2 Tahun 2021, pp.1-9

Tabel 3. Daftar studi literatur

\begin{tabular}{|c|c|c|c|c|}
\hline No & $\begin{array}{l}\text { Nama } \\
\text { Penulis }\end{array}$ & Tahun & $\begin{array}{l}\text { Judul } \\
\text { Penelitian/B } \\
\text { uku }\end{array}$ & $\begin{array}{l}\text { Hasil } \\
\text { Pembahasan }\end{array}$ \\
\hline 1 & $\begin{array}{l}\text { Inge } \\
\text { Bobbin } \\
\mathrm{k}, \\
\text { Suzann } \\
\text { e Loen }\end{array}$ & 2017 & $\begin{array}{l}\text { Water } \\
\text { inSight }\end{array}$ & $\begin{array}{l}\text { Mengenai } \\
\text { layout } \\
\text { penempatan } \\
\text { boezem dan } \\
\text { pompa air. }\end{array}$ \\
\hline 2 & $\begin{array}{l}\text { Handi } \\
\text { Firman } \\
\text { syah } \\
\text { Rahma } \\
\text { nanta }\end{array}$ & 2017 & $\begin{array}{l}\text { Perencanaan } \\
\text { boezem dan } \\
\text { Pompa di } \\
\text { Kawasan } \\
\text { Hilir Kali } \\
\text { Kandangan } \\
\text { Surabaya } \\
\text { Barat }\end{array}$ & $\begin{array}{l}\text { Didapat debit } \\
\text { banjir rencana } \\
\text { dari Sub DAS, } \\
\text { dimensi boezem, } \\
\text { kebutuhan } \\
\text { pompa dan pintu } \\
\text { air, serta } \\
\text { pengoperasian } \\
\text { pompa. }\end{array}$ \\
\hline 3 & $\begin{array}{l}\text { Ayu } \\
\text { Ryan } \\
\text { Prames } \\
\text { wari }\end{array}$ & 2017 & $\begin{array}{l}\text { Evaluasi } \\
\text { Sistem } \\
\text { Drainase dan } \\
\text { Boezem } \\
\text { Bhumi } \\
\text { Marinir } \\
\text { Gunungsari } \\
\text { Surabaya }\end{array}$ & $\begin{array}{l}\text { Hasil evaluasi } \\
\text { meliputi saluran } \\
\text { primer, dimensi } \\
\text { boezem, } \\
\text { kapasitas } \\
\text { pompa, dimensi } \\
\text { pintu air yang } \\
\text { mana perlu } \\
\text { diadakan } \\
\text { perbesaran } \\
\text { dimensi }\end{array}$ \\
\hline 4 & $\begin{array}{l}\text { Rianti } \\
\text { Dwi } \\
\text { Putri, } \\
\text { dkk. }\end{array}$ & 2014 & $\begin{array}{l}\text { Evaluasi } \\
\text { Sistem } \\
\text { Drainase } \\
\text { Daerah } \\
\text { Muara } \\
\text { Boezem } \\
\text { Utara } \\
\text { Morokremba } \\
\text { ngan } \\
\text { Surabaya }\end{array}$ & $\begin{array}{l}\text { Didapat saluran } \\
\text { eksisting yang } \\
\text { kurang } \\
\text { memadai, } \\
\text { adanya } \\
\text { pengaruh } \\
\text { fluktuasi akibat } \\
\text { pasang surut di } \\
\text { hilir Boezem }\end{array}$ \\
\hline 5 & $\begin{array}{l}\text { Dwi } \\
\text { Indriya } \\
\text { ni, dkk. }\end{array}$ & 2019 & $\begin{array}{l}\text { Boezem, } \\
\text { Pompa dan } \\
\text { Pintu Air } \\
\text { sebagai } \\
\text { Pengendali } \\
\text { Banjir di } \\
\text { Kali Balong } \\
\text { Kecamatan } \\
\text { Tandes Kota } \\
\text { Surabaya }\end{array}$ & $\begin{array}{l}\text { Didapat pola } \\
\text { pengoperasian } \\
\text { pompa dan pintu } \\
\text { air dalam } \\
\text { pengoptimalisas } \\
\text { ian fungsi } \\
\text { boezem, pompa } \\
\text { dan pintu air }\end{array}$ \\
\hline
\end{tabular}

\section{Pengumpulan data}

Dalam penentuan pola operasional boezem, pompa dan pintu air, data penting akan sangat diperlukan untuk mendapatkan hasil yang optimal sesuai dengan yang diharapkan. Dalam proposal skripsi ini data yang diperlukan adalah:

- Topografi kawasan studi

- Lokasi stasiun hujan

- $\quad$ Peta Tata Guna Lahan Eksisting

\section{Analisa hidrologi}

Analisa hidrologi merupakan hasil hitung data-data primer yang telah terkumpul. Analisa hidrologi yang dimaksud meliputi:

- Menghitung Curah Hujan Rata-rata

- Menghitung Tinggi Hujan Rata-rata

- Menghitung Hidrograf Banjir

\section{Analisa hidrolika}

Analisa Hidrolika meliputi:

- Kapasitas boezem

- Perhitungan debit inflow dan outflow

Selain itu juga ditambah perencanaan utama

- Perencanaan pintu air dan kapasitas pompa

- Perhitungan flood routing

\section{Diagram alir}
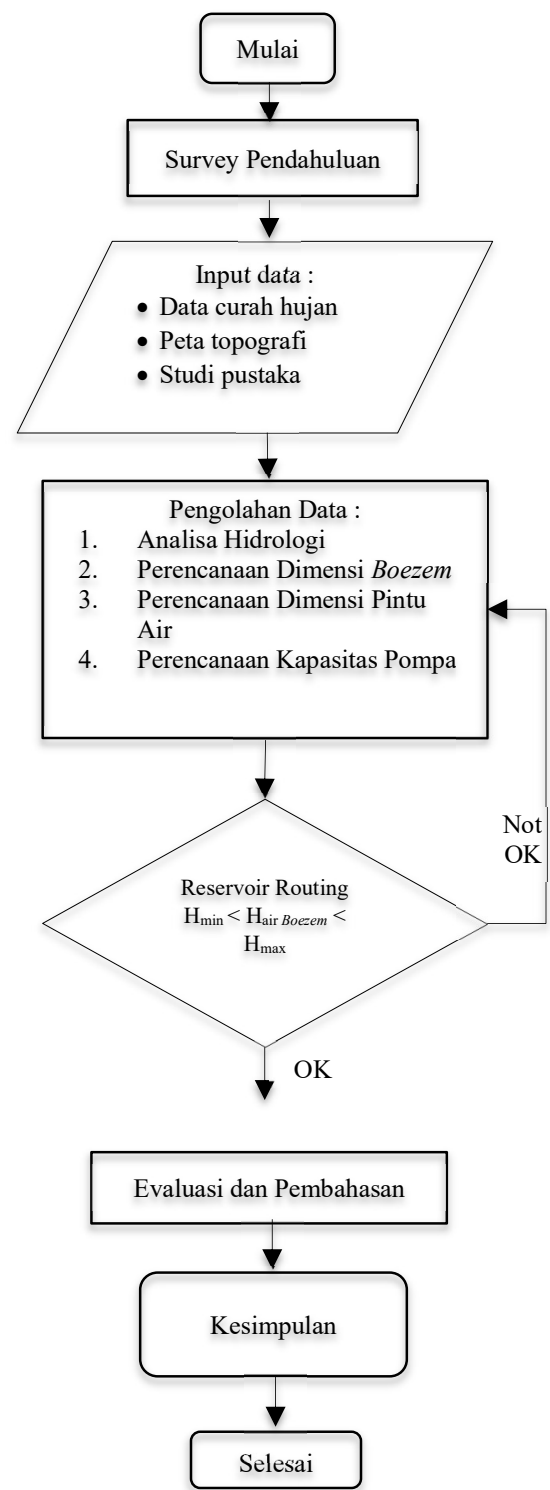


\section{JURNAL SONDIR}

p-ISSN 1979-2832

e-ISSN 2746-8275

https://ejournal.itn.ac.id/index.php/sondir

vol. 5 No. 2 Tahun 2021, pp.1-9

\section{HASIL ANALISA DAN PEMBAHASAN}

\section{Perhitungan curah hujan maksimal dan hujan} rerata

Berikut merupakan data curah hujan hari maksimum dari ketiga stasiun hujan

Tabel 4. Nilai curah hujan maksimum

\begin{tabular}{|c|c|c|c|c|c|c|c|}
\hline \multicolumn{8}{|c|}{$\begin{array}{l}\text { CURAH HUJAN MAKSIMAL DAN HUJAN } \\
\text { RERATA }\end{array}$} \\
\hline $\begin{array}{l}\mathrm{N} \\
\mathrm{O}\end{array}$ & $\begin{array}{l}\text { TAN } \\
\text { GGA } \\
\text { L }\end{array}$ & $\begin{array}{l}\text { Sta } \\
\mathrm{La} \\
\text { wa } \\
\text { ng }\end{array}$ & $\begin{array}{l}\text { St } \\
\mathrm{a} \\
\mathrm{Tu} \\
\text { tur }\end{array}$ & $\begin{array}{l}\text { Sta } \\
\text { Won } \\
\text { orej } \\
\text { o }\end{array}$ & $\begin{array}{l}\text { JUM } \\
\text { LA } \\
\text { H }\end{array}$ & $\begin{array}{l}\text { Ra } \\
\text { ta- } \\
\text { Ra } \\
\text { ta }\end{array}$ & $\begin{array}{l}\text { Pol } \\
\text { ygo } \\
\mathrm{n} \\
\text { Thi } \\
\text { esse } \\
\mathrm{n}\end{array}$ \\
\hline 1 & 2007 & 68 & 92 & 80 & 240 & $\begin{array}{l}80 . \\
00\end{array}$ & $\begin{array}{l}78.6 \\
314\end{array}$ \\
\hline 2 & 2008 & 114 & 98 & 117 & 329 & $\begin{array}{l}10 \\
9.6 \\
7 \\
\end{array}$ & $\begin{array}{l}107 . \\
942\end{array}$ \\
\hline 3 & 2009 & 36 & 75 & 96 & 207 & $\begin{array}{l}69 . \\
00\end{array}$ & $\begin{array}{l}57.0 \\
684 \\
\end{array}$ \\
\hline 4 & 2010 & 120 & 95 & 166 & 381 & $\begin{array}{l}12 \\
7.0 \\
0\end{array}$ & $\begin{array}{l}114 . \\
403\end{array}$ \\
\hline 5 & 2011 & 90 & 81 & 72 & 243 & $\begin{array}{l}81 . \\
00\end{array}$ & $\begin{array}{l}84.7 \\
491\end{array}$ \\
\hline 6 & 2012 & 144 & 85 & 100 & 329 & $\begin{array}{l}10 \\
9.6 \\
7\end{array}$ & $\begin{array}{l}116 . \\
507\end{array}$ \\
\hline 7 & 2013 & 117 & 85 & 77 & 279 & $\begin{array}{l}93 . \\
00\end{array}$ & $\begin{array}{l}100 . \\
577\end{array}$ \\
\hline 8 & 2014 & 108 & $\begin{array}{l}11 \\
5\end{array}$ & 70 & 293 & $\begin{array}{l}97 . \\
67\end{array}$ & $\begin{array}{l}107 . \\
215\end{array}$ \\
\hline 9 & 2015 & 141 & $\begin{array}{l}18 \\
0\end{array}$ & 67 & 388 & $\begin{array}{l}12 \\
9.3 \\
3 \\
\end{array}$ & $\begin{array}{l}149 . \\
521\end{array}$ \\
\hline $\begin{array}{l}1 \\
0\end{array}$ & 2016 & 124 & $\begin{array}{l}12 \\
4\end{array}$ & 125 & 373 & $\begin{array}{l}12 \\
4.3 \\
3 \\
\end{array}$ & $\begin{array}{l}124 . \\
094\end{array}$ \\
\hline & MLAH & $\begin{array}{l}106 \\
2\end{array}$ & $\begin{array}{l}10 \\
30\end{array}$ & 970 & 3062 & $\begin{array}{l}10 \\
20 . \\
7\end{array}$ & \\
\hline & a- Rata & $\begin{array}{l}106 \\
.2\end{array}$ & $\begin{array}{l}10 \\
3\end{array}$ & 97 & $\begin{array}{l}306 . \\
2\end{array}$ & $\begin{array}{l}10 \\
2.0 \\
7\end{array}$ & \\
\hline
\end{tabular}

Sumber: Perhitungan

Dengan:

$$
\begin{array}{ll}
\mathrm{X}^{2} & \text { : nilai chi-square } \\
\mathrm{Ej} & : \text { Frekuensi teoritis kelas } \mathrm{j} \\
\mathrm{Oj} & : \text { Frekuensi pengamatan kelas j }
\end{array}
$$

\section{Perhitungan curah hujan rencana}

Berdasarkan hasil uji kecocokan E.J Gumbel dan Log Pearson III, perhitungan yang digunakan adalah perhitungan curah hujan metode Log Pearson III. Yang mana petabulasian hasilnya sebagai berikut:

- Metode Log Pearson III

\begin{tabular}{|c|c|c|c|c|c|}
\hline No. & Tahun & $\begin{array}{l}\text { Tinggi } \\
\text { Hujan } \\
\text { (R) }\end{array}$ & $\log X$ & $\begin{array}{l}(\log X \\
\left(\log X_{\text {rerata }}\right)^{2}\end{array}$ & $\begin{array}{l}(\log X \quad- \\
\log \\
\left.X_{\text {rerata }}\right)^{3}\end{array}$ \\
\hline 1 & 2007 & 80.0 & 1.903 & 0.009370329 & $\begin{array}{l}- \\
0.00090705\end{array}$ \\
\hline 2 & 2008 & 109.7 & 2.040 & 0.001614770 & 0.00006489 \\
\hline 3 & 2009 & 69.0 & 1.839 & 0.025934318 & $\begin{array}{l}- \\
0.00417650\end{array}$ \\
\hline 4 & 2010 & 127.0 & 2.104 & 0.010797969 & 0.00112205 \\
\hline 5 & 2011 & 81.0 & 1.908 & 0.008354952 & $\begin{array}{l}- \\
0.00076369\end{array}$ \\
\hline 6 & 2012 & 109.7 & 2.040 & 0.001614770 & 0.00006489 \\
\hline 7 & 2013 & 93.0 & 1.968 & 0.000986431 & $\overline{-}-00003098$ \\
\hline 8 & 2014 & 97.7 & 1.990 & 0.000102902 & $\begin{array}{l}- \\
0.00000104\end{array}$ \\
\hline 9 & 2015 & 129.3 & 2.112 & 0.012503718 & 0.00139817 \\
\hline 10 & 2016 & 124.3 & 2.095 & 0.008967547 & 0.00084920 \\
\hline \multicolumn{2}{|c|}{ Jumlah } & & 19.9989 & 0.080247705 & $\begin{array}{l}- \\
0.00238007\end{array}$ \\
\hline \multicolumn{2}{|c|}{ Rerata } & & 1.9999 & & \\
\hline \multicolumn{2}{|c|}{$\begin{array}{l}\text { Standart } \\
\text { Deviasi }\end{array}$} & \multicolumn{4}{|l|}{0.0944} \\
\hline \multicolumn{2}{|l|}{ Cs } & \multicolumn{4}{|c|}{-0.39262} \\
\hline
\end{tabular}

Tabel 5. Hasil perhitungan nilai Log, standar deviasi, dan koefisien kemencengan

Sumber: perhitungan

Tabel 6. Nilai curah hujan rancangan metode Log Pearson III

\begin{tabular}{|l|l|l|l|l|}
\hline $\operatorname{Tr}$ & $\mathrm{P}(\%)$ & $\mathrm{K}$ & K.SD & $\begin{array}{l}\text { X } \\
\text { rancangan } \\
(\mathrm{mm})\end{array}$ \\
\hline 100 & 1 & 2.029 & 0.192 & 155.411 \\
\hline 50 & 2 & 1.834 & 0.173 & 148.960 \\
\hline 20 & 5 & 1.179 & 0.111 & 129.187 \\
\hline 10 & 10 & 1.231 & 0.116 & 130.656 \\
\hline 5 & 20 & 0.855 & 0.081 & 120.400 \\
\hline 2 & 50 & 0.066 & 0.006 & 101.420 \\
\hline
\end{tabular}

Sumber : Hasil Perhitungan

- Metode EJ. Gumbel

Tabel 7. Hasil rekap perhitungan curah hujan rancangan metode EJ. Gumbel dan Log Person Tipe III

\begin{tabular}{|l|l|l|}
\hline periode & E.J Gumbel & $\begin{array}{l}\text { Log-Pearson } \\
\text { III }\end{array}$ \\
\hline 2 & 107,332 & 97,332 \\
\hline 5 & 144,040 & 110,173 \\
\hline
\end{tabular}


JURNAL SONDIR

p-ISSN 1979-2832

e-ISSN 2746-8275

https://ejournal.itn.ac.id/index.php/sondir

vol. 5 No. 2 Tahun 2021, pp.1-9

\begin{tabular}{|l|l|l|}
\cline { 2 - 3 } 10 & 168,344 & 116,876 \\
\hline 20 & 191,657 & 115,925 \\
\hline 50 & 221,833 & 128,486 \\
\hline 100 & 244,446 & 132,483 \\
\hline
\end{tabular}

Sumber : Hasil Perhitungan

Perhitungan debit banjir rancangan

Tabel 8. Hasil perhitungan debit rasional

\begin{tabular}{|c|c|c|c|c|c|c|c|c|c|c|}
\hline \multirow{2}{*}{$\begin{array}{l}\mathrm{N} \\
\mathrm{o}\end{array}$} & $\begin{array}{l}\text { Per } \\
\text { iod } \\
\mathrm{e} \\
\text { Ula } \\
\text { ng }\end{array}$ & A & $\mathrm{R}$ & $\mathrm{L}$ & $\mathrm{H}$ & \multirow[t]{2}{*}{ C } & V & $\mathrm{t}$ & I & \multirow[t]{2}{*}{ Q } \\
\hline & $\begin{array}{l}\text { tah } \\
\text { un }\end{array}$ & ${ }_{2}^{\mathrm{km}}$ & $\mathrm{mm}$ & $\begin{array}{l}\mathrm{k} \\
\mathrm{m}\end{array}$ & $\mathrm{km}$ & & $\begin{array}{l}\mathrm{km} \\
/ \mathrm{ja} \\
\mathrm{m}\end{array}$ & jam & $\begin{array}{l}\mathrm{mm} \\
/ \mathrm{ja} \\
\mathrm{m}\end{array}$ & \\
\hline 1 & 2 & $\begin{array}{l}49 \\
9,8 \\
0 \\
\end{array}$ & $\begin{array}{l}107, \\
332 \\
3\end{array}$ & $\begin{array}{l}3 \\
1,\end{array}$ & $\begin{array}{l}0,3 \\
10 \\
5\end{array}$ & $\begin{array}{l}0 \\
2 \\
\end{array}$ & $\begin{array}{l}1,1 \\
44 \\
0\end{array}$ & $\begin{array}{l}27 \\
273 \\
4\end{array}$ & $\begin{array}{l}4,1 \\
068\end{array}$ & $\begin{array}{l}114, \\
122 \\
4\end{array}$ \\
\hline 2 & 5 & $\begin{array}{l}49 \\
9,8 \\
0 \\
\end{array}$ & $\begin{array}{l}144, \\
040 \\
2 \\
\end{array}$ & $\begin{array}{l}3 \\
1, \\
2\end{array}$ & $\begin{array}{l}0,3 \\
10 \\
5 \\
\end{array}$ & $\begin{array}{l}0 \\
2 \\
2\end{array}$ & $\begin{array}{l}1,1 \\
44 \\
0\end{array}$ & $\begin{array}{l}27, \\
273 \\
4\end{array}$ & $\begin{array}{l}5,5 \\
113\end{array}$ & $\begin{array}{l}153, \\
152 \\
7 \\
\end{array}$ \\
\hline 3 & 10 & $\begin{array}{l}49 \\
9,8 \\
0\end{array}$ & $\begin{array}{l}168, \\
344 \\
1\end{array}$ & $\begin{array}{l}1, \\
2\end{array}$ & $\begin{array}{l}0,3 \\
10 \\
5 \\
\end{array}$ & $\begin{array}{l}0 \\
2 \\
\end{array}$ & $\begin{array}{l}1,1 \\
44 \\
0\end{array}$ & $\begin{array}{l}27, \\
273 \\
4\end{array}$ & $\begin{array}{l}6,4 \\
412\end{array}$ & $\begin{array}{l}178, \\
994 \\
1\end{array}$ \\
\hline 4 & 20 & $\begin{array}{l}49 \\
9,8 \\
0 \\
\end{array}$ & $\begin{array}{l}191, \\
656 \\
9\end{array}$ & $\begin{array}{l}3 \\
1, \\
2\end{array}$ & $\begin{array}{l}0,3 \\
10 \\
5\end{array}$ & $\begin{array}{l}0 \\
2 \\
2\end{array}$ & $\begin{array}{l}1,1 \\
44 \\
0\end{array}$ & $\begin{array}{l}27 \\
273 \\
4\end{array}$ & $\begin{array}{l}7,3 \\
332\end{array}$ & $\begin{array}{l}203, \\
781 \\
8\end{array}$ \\
\hline 5 & 50 & $\begin{array}{l}49 \\
9,8 \\
0\end{array}$ & $\begin{array}{l}221, \\
833 \\
0\end{array}$ & $\begin{array}{l}3 \\
1, \\
2\end{array}$ & $\begin{array}{l}0,3 \\
10 \\
5\end{array}$ & $\begin{array}{l}0 \\
2 \\
2\end{array}$ & $\begin{array}{l}1,1 \\
44 \\
0\end{array}$ & $\begin{array}{l}27, \\
273 \\
4\end{array}$ & $\begin{array}{l}8,4 \\
878\end{array}$ & $\begin{array}{l}235 \\
866 \\
9\end{array}$ \\
\hline 6 & $\begin{array}{l}10 \\
0\end{array}$ & $\begin{array}{l}49 \\
9,8 \\
0 \\
\end{array}$ & $\begin{array}{l}244, \\
445 \\
7 \\
\end{array}$ & $\begin{array}{l}3 \\
1, \\
2\end{array}$ & $\begin{array}{l}0,3 \\
10 \\
5\end{array}$ & $\begin{array}{l}0 \\
2\end{array}$ & $\begin{array}{l}1,1 \\
44 \\
0\end{array}$ & $\begin{array}{l}27, \\
273 \\
4\end{array}$ & $\begin{array}{l}9,3 \\
530\end{array}$ & $\begin{array}{l}259, \\
910 \\
2 \\
\end{array}$ \\
\hline
\end{tabular}

Sumber: Hasil Perhitungan

\section{Perencanaan boezem, pompa dan pintu air}

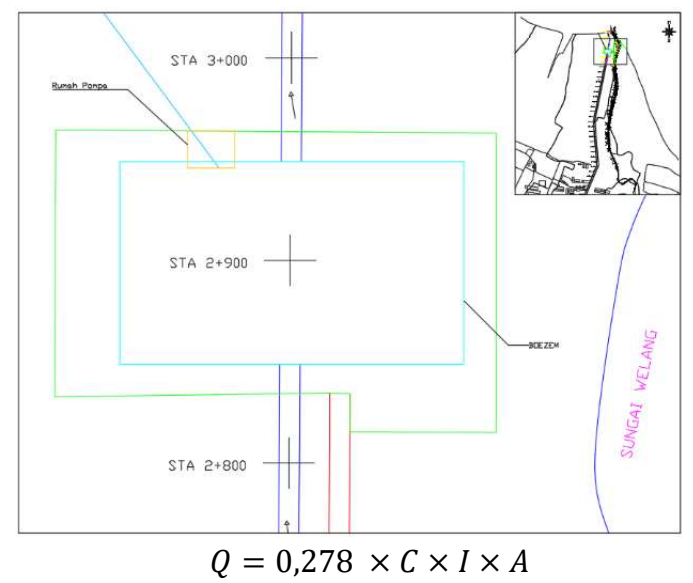

Perencanaan saluran ini dimaksudkan agar boezem mendapatkan aliran air yang diakibatkan banjir rencana.
Tabel 9. Data elevasi dan rencana saluran

\begin{tabular}{|c|c|c|c|c|c|}
\hline \multirow{3}{*}{ STA } & \multicolumn{4}{|c|}{ SALURAN RENCANA } & \multirow{3}{*}{$\begin{array}{l}\text { EL. } \\
\text { MUKA } \\
\text { TANAH }\end{array}$} \\
\hline & B & $\mathrm{H}$ & $\mathrm{A}$ & $\mathrm{P}$ & \\
\hline & $\bar{m}$ & $\mathrm{~m}$ & $\mathrm{~m}^{2}$ & $\mathrm{~m}$ & \\
\hline $0+000$ & 1.00 & 1.00 & 1.00 & 3.00 & +4.20 \\
\hline $0+100$ & 1.00 & 1.00 & 1.00 & 3.00 & +3.90 \\
\hline $0+200$ & 1.00 & 1.00 & 1.00 & 3.00 & +3.65 \\
\hline $0+300$ & 1.00 & 1.00 & 1.00 & 3.00 & +3.40 \\
\hline $0+400$ & 1.00 & 1.00 & 1.00 & 3.00 & +3.20 \\
\hline $0+500$ & 1.00 & 1.00 & 1.00 & 3.00 & +3.10 \\
\hline $0+600$ & 1.00 & 1.00 & 1.00 & 3.00 & +3.05 \\
\hline $0+700$ & 1.00 & 1.00 & 1.00 & 3.00 & +3.00 \\
\hline $0+800$ & 1.00 & 1.00 & 1.00 & 3.00 & +2.00 \\
\hline $0+900$ & 1.00 & 1.00 & 1.00 & 3.00 & +2.10 \\
\hline $1+000$ & 1.00 & 1.00 & 1.00 & 3.00 & +1.80 \\
\hline $1+100$ & 1.00 & 1.00 & 1.00 & 3.00 & +3.00 \\
\hline $1+200$ & 1.00 & 1.00 & 1.00 & 3.00 & +2.80 \\
\hline $1+300$ & 1.00 & 1.00 & 1.00 & 3.00 & +2.50 \\
\hline $1+400$ & 1.00 & 1.00 & 1.00 & 3.00 & +2.80 \\
\hline $1+500$ & 1.00 & 1.00 & 1.00 & 3.00 & +3.00 \\
\hline $1+600$ & 1.00 & 1.00 & 1.00 & 3.00 & +2.50 \\
\hline $1+700$ & 1.00 & 1.00 & 1.00 & 3.00 & +1.90 \\
\hline $1+800$ & 1.00 & 1.00 & 1.00 & 3.00 & +1.80 \\
\hline $1+900$ & 1.00 & 1.00 & 1.00 & 3.00 & +1.75 \\
\hline $2+000$ & 1.00 & 1.00 & 1.00 & 3.00 & +1.76 \\
\hline $2+100$ & 1.00 & 1.00 & 1.00 & 3.00 & +1.60 \\
\hline $2+200$ & 1.00 & 1.00 & 1.00 & 3.00 & +1.50 \\
\hline $2+300$ & 1.00 & 1.00 & 1.00 & 3.00 & +1.46 \\
\hline $2+400$ & 1.00 & 1.00 & 1.00 & 3.00 & +1.43 \\
\hline $2+500$ & 1.00 & 1.00 & 1.00 & 3.00 & +1.40 \\
\hline $2+600$ & 1.00 & 1.00 & 1.00 & 3.00 & +1.34 \\
\hline $2+700$ & 1.00 & 1.00 & 1.00 & 3.00 & +1.33 \\
\hline $2+800$ & 1.00 & 1.00 & 1.00 & 3.00 & +1.30 \\
\hline
\end{tabular}

Sumber: Perhitungan

Keterangan:
B : Lebar saluran rencana
$\mathrm{H} \quad$ : Panjang saluran rencana
A : Luas saluran rencana
P : keliling basah saluran 


\section{JURNAL SONDIR}

p-ISSN 1979-2832

e-ISSN 2746-8275

https://ejournal.itn.ac.id/index.php/sondir

vol. 5 No. 2 Tahun 2021, pp.1-9

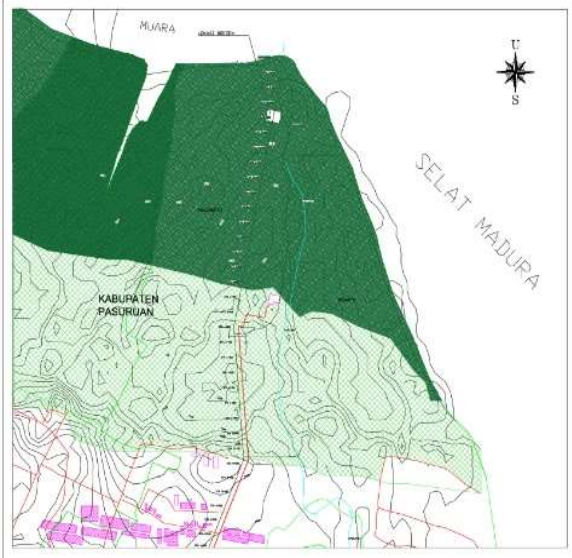

Gambar 2. Tata guna lahan lokasi studi

Tabel 10. Nilai koefisien pengaliran gabungan

\begin{tabular}{|c|c|c|c|c|c|}
\hline \multirow{2}{*}{$\mathrm{N}$} & \multirow{2}{*}{$\begin{array}{l}\text { Jenis Tata } \\
\text { Guna lahan }\end{array}$} & \multicolumn{2}{|c|}{ A } & \multirow[b]{2}{*}{ C } & \multirow{2}{*}{$\begin{array}{c}\text { C } \\
\text { GABUNG } \\
\text { AN }\end{array}$} \\
\hline & & $\mathrm{m} 2$ & $\%$ & & \\
\hline 1 & $\begin{array}{c}\text { Jalan } \\
\text { beraspal }\end{array}$ & 1200 & $\begin{array}{l}21 \\
\%\end{array}$ & 0.9 & 0.1882 \\
\hline 2 & $\begin{array}{c}\text { Daerah } \\
\text { perumahan }\end{array}$ & 1093 & $\begin{array}{l}19 \\
\%\end{array}$ & 0.7 & 0.1333 \\
\hline 3 & Sawah & $\begin{array}{c}1716 \\
.4\end{array}$ & $\begin{array}{l}30 \\
\%\end{array}$ & 0.2 & 0.0598 \\
\hline 4 & Rawa-rawa & $\begin{array}{c}1729 \\
.4 \\
\end{array}$ & $\begin{array}{l}30 \\
\%\end{array}$ & $\begin{array}{c}0.1 \\
2 \\
\end{array}$ & 0.0362 \\
\hline & Total & $\begin{array}{c}5738 \\
.8\end{array}$ & $\begin{array}{c}100 \\
\%\end{array}$ & & 0.4175 \\
\hline
\end{tabular}

Sumber: perhitungan

Keterangan:

A: Luas daerah

$\mathrm{C}$ : Koefisien pengaliran pada daerah tertentu

Penelusuran Banjir (Flood Routing)

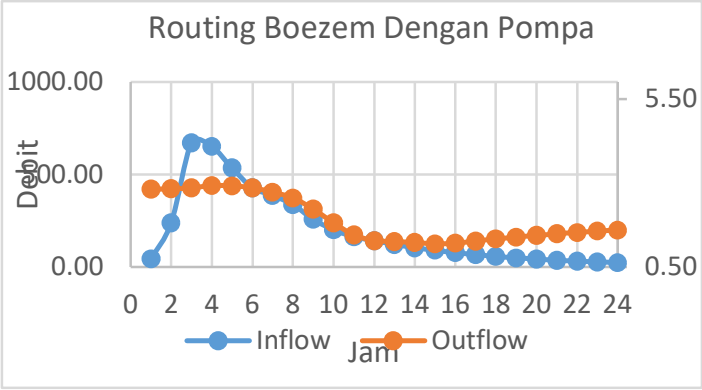

Gambar 3. Routing dengan Pompa

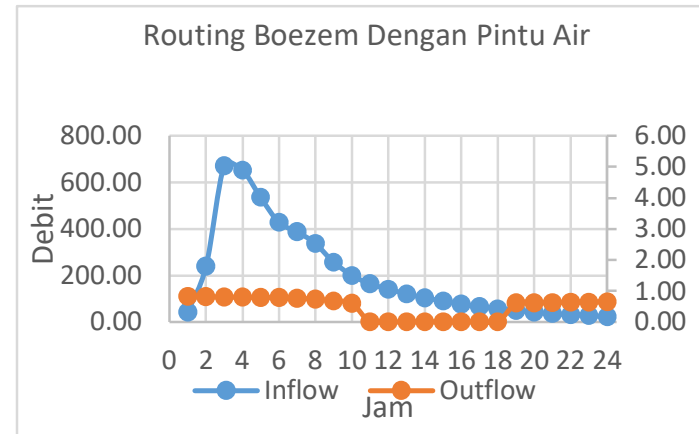

Gambar 4. Routing dengan Pintu Air

Tabel 11. Routing boezem dengan pintu air

\begin{tabular}{|c|c|c|c|c|c|c|c|c|}
\hline $\begin{array}{c}\text { Peri } \\
\text { ode } \\
\text { Rout } \\
\text { ing }\end{array}$ & $\begin{array}{l}\text { Wa } \\
\text { ktu }\end{array}$ & $\begin{array}{c}\text { Qinflo } \\
w\end{array}$ & $\begin{array}{c}\text { Ting } \\
\text { gi } \\
\text { Muk } \\
\text { a Air } \\
\text { Boez } \\
\text { em }\end{array}$ & $\begin{array}{c}\text { Ting } \\
\text { gi } \\
\text { Buk } \\
\text { aan } \\
\text { Pint } \\
\text { u }\end{array}$ & $\begin{array}{l}\text { Qoutfl } \\
\text { ow } \\
\text { pintu }\end{array}$ & $\begin{array}{l}\text { Volu } \\
\text { me }\end{array}$ & $\begin{array}{l}\text { TIng } \\
\text { gi Air } \\
\text { Outfl } \\
\text { ow }\end{array}$ & $\begin{array}{c}\text { Kont } \\
\text { rol }\end{array}$ \\
\hline & $\begin{array}{l}\text { (ja } \\
\mathrm{m}) \\
\end{array}$ & $\begin{array}{c}(\mathrm{m} 3 / \mathrm{d} \\
\text { etik) }\end{array}$ & (m) & $\mathrm{m}$ & $\begin{array}{c}(\mathrm{m} 3 / \mathrm{d} \\
\text { etik) }\end{array}$ & (m3) & $(\mathrm{m})$ & \\
\hline [1] & [2] & [3] & [4] & [5] & [6] & [7] & [8] & [9] \\
\hline 1 & 1 & 43.32 & 2.82 & 0.50 & $\begin{array}{c}3.883 \\
17 \\
\end{array}$ & $\begin{array}{r}1397 \\
9.42 \\
\end{array}$ & 0.82 & OK \\
\hline 2 & 2 & 239.5 & 2.77 & 0.50 & 3.848 & $\begin{array}{l}1385 \\
3.76\end{array}$ & 0.81 & OK \\
\hline 3 & 3 & $\begin{array}{c}671.1 \\
6\end{array}$ & 2.71 & 0.50 & $\begin{array}{c}3.803 \\
52\end{array}$ & $\begin{array}{l}1369 \\
2.67\end{array}$ & 0.81 & OK \\
\hline 4 & 4 & $\begin{array}{c}651.8 \\
0\end{array}$ & 2.65 & 0.50 & $\begin{array}{c}3.761 \\
32\end{array}$ & $\begin{array}{l}1354 \\
0.76\end{array}$ & 0.80 & OK \\
\hline 5 & 5 & $\begin{array}{c}535.4 \\
5\end{array}$ & 2.61 & 0.50 & $\begin{array}{c}3.735 \\
1\end{array}$ & $\begin{array}{l}1344 \\
6.34\end{array}$ & 0.79 & OK \\
\hline 6 & 6 & $\begin{array}{c}427.9 \\
1\end{array}$ & 2.55 & 0.50 & $\begin{array}{c}3.688 \\
88\end{array}$ & $\begin{array}{l}1327 \\
9.97\end{array}$ & 0.78 & OK \\
\hline 7 & 7 & $\begin{array}{c}387.3 \\
2 \\
\end{array}$ & 2.43 & 0.50 & $\begin{array}{c}3.600 \\
3 \\
\end{array}$ & $\begin{array}{l}1296 \\
1.06 \\
\end{array}$ & 0.76 & OK \\
\hline 8 & 8 & $\begin{array}{c}337.4 \\
2\end{array}$ & 2.25 & 0.50 & $\begin{array}{c}3.466 \\
26\end{array}$ & $\begin{array}{l}1247 \\
8.54\end{array}$ & 0.73 & OK \\
\hline 9 & 9 & $\begin{array}{c}257.2 \\
5\end{array}$ & 1.92 & 0.50 & $\begin{array}{c}3.201 \\
26\end{array}$ & $\begin{array}{l}1152 \\
4.55 \\
\end{array}$ & 0.68 & OK \\
\hline 10 & 10 & $\begin{array}{c}199.7 \\
6\end{array}$ & 1.51 & 0.50 & $\begin{array}{c}2.840 \\
01\end{array}$ & $\begin{array}{l}1022 \\
4.03\end{array}$ & 0.60 & OK \\
\hline 11 & 11 & $\begin{array}{c}163.4 \\
5 \\
\end{array}$ & 1.15 & 0.00 & 0 & 0.00 & 0.00 & OK \\
\hline 12 & 12 & $\begin{array}{c}140.8 \\
3\end{array}$ & 1.13 & 0.00 & 0 & 0.00 & 0.00 & OK \\
\hline 13 & 13 & $\begin{array}{c}120.8 \\
7 \\
\end{array}$ & 1.16 & 0.00 & 0 & 0.00 & 0.00 & OK \\
\hline 14 & 14 & $\begin{array}{c}103.9 \\
9 \\
\end{array}$ & 1.19 & 0.00 & 0 & 0.00 & 0.00 & OK \\
\hline 15 & 15 & 89.72 & 1.27 & 0.00 & 0 & 0.00 & 0.00 & OK \\
\hline 16 & 16 & 77.05 & 1.34 & 0.00 & 0 & 0.00 & 0.00 & OK \\
\hline 17 & 17 & 66.12 & 1.41 & 0.00 & 0 & 0.00 & 0.00 & OK \\
\hline 18 & 18 & 56.78 & 1.47 & 0.00 & 0 & 0.00 & 0.00 & OK \\
\hline 19 & 19 & 49.04 & 1.53 & 0.50 & $\begin{array}{c}2.854 \\
94\end{array}$ & $\begin{array}{l}1027 \\
7.80\end{array}$ & 0.60 & OK \\
\hline 20 & 20 & 42.39 & 1.58 & 0.50 & $\begin{array}{c}2.902 \\
36 \\
\end{array}$ & $\begin{array}{l}1044 \\
8.50 \\
\end{array}$ & 0.61 & OK \\
\hline 21 & 21 & 36.27 & 1.62 & 0.50 & $\begin{array}{c}2.944 \\
64\end{array}$ & $\begin{array}{l}1060 \\
0.72\end{array}$ & 0.62 & OK \\
\hline 22 & 22 & 31.36 & 1.66 & 0.50 & $\begin{array}{c}2.982 \\
3\end{array}$ & $\begin{array}{l}1073 \\
6.29\end{array}$ & 0.63 & OK \\
\hline 23 & 23 & 26.93 & 1.70 & 0.50 & $\begin{array}{c}3.015 \\
9\end{array}$ & $\begin{array}{l}1085 \\
7.26 \\
\end{array}$ & 0.64 & OK \\
\hline 24 & 24 & 23.21 & 1.74 & 0.50 & $\begin{array}{c}3.045 \\
8\end{array}$ & $\begin{array}{l}1096 \\
4.89\end{array}$ & 0.64 & OK \\
\hline
\end{tabular}

Sumber: Perhitungan 


\section{JURNAL SONDIR}

p-ISSN 1979-2832

e-ISSN 2746-8275

https://ejournal.itn.ac.id/index.php/sondir vol. 5 No. 2 Tahun 2021, pp.1-9

\section{KESIMPULAN DAN SARAN}

Dari perhitungan perencanaan yang telah dijabarkan pada sub-bab sebelumnya didapatkan simpulan sebagai berikut:

a) Debit banjir rancangan pada subdas sungai Welang dengan periode ulang 2 tahun sebesar $114,1224 \mathrm{~m}^{3} /$ detik, 5 tahun sebesar 153,1527 $\mathrm{m}^{3} /$ detik, 10 tahun sebesar 178,9941 m³/detik, 20 tahun sebesar 203,7818 $\mathrm{m}^{3} /$ detik, 50 tahun sebesar 235,8669 $\mathrm{m}^{3}$ detik, 100 tahun sebesar $259,9102 \mathrm{~m}^{3} /$ detik.

b) Didapatkan dari hasil perhitungan perencanaan mengenai pendimensian boezem adalah lebar sebesar $170 \mathrm{~m}$, panjang sebesar $100 \mathrm{~m}$, dan kedalaman sebesar $3 \mathrm{~m}$. Untuk jenis pompa yang digunakan adalah Grundfos submersible pump type $S$ - Range $78,520 \mathrm{~kW}$ dengan kapasitas maksimal $6600 \mathrm{~m}^{3} / \mathrm{jam}$. Dan untuk dimensi pintu air sendiri yakni dengan lebar 1,25 m, tinggi daun pintu $1,50 \mathrm{~m}$, tebal daun pintu $30 \mathrm{~mm}$.

c) Jumlah pompa dan pintu air yang dapat mengoptimalkan kinerja boezem adalah sebanyak 2 buah pompa air dan 2 buah pintu air.

d) Pola Pengoperasian Boezem berdasarkan ketinggian air yang ada pada boezem boezem yakni pada rentan ketinggian $0,00 \mathrm{~m}$ hingga 1,20 $\mathrm{m}$, pintu dan pompa air tidak aktif. Pada rentan ketinggian air 1,20 $\mathrm{m}$ hingga 2,00 m, pompa air nomor 1 aktif dan pintu nomor 1 dibuka. Dan pada rentan ketinggian air 2,00 m hingga $2,85 \mathrm{~m}$, pompa nomor 2 dan kedua pintu dibuka.

Saran yang dapat diberikan dalam perencanaan boezem dan pompa air sebagai berikut:

a) Perlunya perawatan berkala pada boezem, pompa air dan pintu. Agar sistem pembuangan tetap lancar.

b) Diperlukan perhatian terhadap operator pompa air terutama dalam pengoperasian dan aspek teknis lainya, agar pompa tetap dapat bekerja secara optimal.

\section{DAFTAR PUSTAKA}

Anonim, (2016). Tutorial Pembuatan Peta Dengan Aplikasi Arcgis 10.2 (Digitasi dan Layout).

A. \& W., (2015). Penelusuran Banjir Menggunakan Metode Level Pool Routing pada Waduk Kota Lhokseumawe. Teras Jurnal, Volume 5.

Bobbink, I. \& Loen, S., (2017). Water inSight: An exploration into landscape architectonic transformations of polder water. Delft: TU Delft, Architecture.

BPS Kabupaten Pasuruan, (2020). Kabupaten Pasuruan Dalam Angka. Pasuruan: BPS Kabupaten Pasuruan.
Chouw, V. T., (1959). Open-Channel Hydraulics. Tokyo: Kogakusha Company, LTD.

Geoportal, I., (2011). Geospasial Indonesia. [Online] Available at: https://tanahair.indonesia.go.id/portal-web

Hindarko, S., (2000). Drainase Perkotaan. s.1.:Penerbit Esha.

Kementrian Pekerjaan Umum Republik Indonesia, (2014). Peraturan Menteri Pekerjaan Umum Republik Indonesia Nomor 12/PRT/M/2014. Jakarta, Kementrian Pekerjaan Umum Republik Indonesia.

PT. Grundfos Trading Indonesia, (. Grundfos Data Booklet S Pumps, Range 72, 74, 78. https://api.grundfos.com/literature/Grundfosliteratur e-3081211.pdf

PT. Grundfos Trading Indonesia, t.thn. Grundfos Product Selection. https:/productselection.grundfos.com/id/products/s/range-78-520-

$\mathrm{kw}$ ?tab $=$ documentation

Purnomo, H., Perencanaan Boezem Sebagai Bangunan Pengendali Banjir di Daerah Jl. Sentosa Kel. Sungai pinang Dalam Samarinda.

Putra, S. M., Pemrograman Komputer Dasar Grafik dan Logika. s.l.:Teknik Pengairan Fakultas Teknik Universitas Brawijaya.

Rachmadhini, I. D., Purwanti, H. \& Prakoso, W. G.,. Desain Sistem Drainase Kawasan Situ Rawa Besar Kampung Lio Kota Depok.

Rahmananta, H. F., (2017). Skripsi Perencanaan Boezem dan Pompa di Kawasan Hilir Kandangan Surabaya. Surabaya: s.n.

Sari, R. L., Lasminto, U. \& Margini, N. F., (2017). Perencanaan Jaringan Drainase Sub Sistem Kalidami Surabaya. Jurnal Teknik Hidroteknik, Volume 2.

Soemarto, C. D., (1987). Hidrologi Teknik. Surabaya: Usaha Nasional.

S., Suhartanto, E. \& Hariwibowo, R., (2017) Penanganan Genangan dengan Sistem Polder pada Wilayah Kota Banjarmasin. Jurnal Teknik Pengairan, pp. 15-25.

Thioritz, S., (2009). Metode Pendekatan Penelusuran Banjir. Makassar: Universitas Atma Jaya Makassar.

Wilson, E. M., (1989). Hidrologi Teknik. 4th penyunt. Bandung: Penerbit ITB Bandung. 